\title{
Innovation in organisational control systems: toward greater accountability
}

\section{Carlos Martin-Rios}

Ecole hôtelière de Lausanne, HES-SO,

University of Applied Sciences Western Switzerland,

Route de Cojonnex 18, 1000 Lausanne 25, Switzerland

Email: carlos.martin-rios@ehl.ch

\begin{abstract}
Organisational control systems are a central phenomenon, yet despite their significance, top-down command-and-control approaches often dominate research. This surmise creates no problem in hierarchical organisations where everyone knows their work duties and what is expected of them. However, it becomes troublesome in knowledge work, where the sets of tasks carried out by any two members of the organisation differ significantly. The article offers conceptual insights elucidating control systems based on the notion of accountability; which help to raise awareness and mobilise efforts beyond the boundaries of long-established hierarchical control. Implications for the theory and practice of organisational control are discussed.
\end{abstract}

Keywords: organisational control; accountability; innovation; knowledge work; management; control theory; collaboration; contribution; control systems; hierarchical control; theoretical paper; knowledge organisation; business performance management; performance management.

Reference to this paper should be made as follows: Martin-Rios, C. (2015) 'Innovation in organisational control systems: toward greater accountability', Int. J. Business Performance Management, Vol. 16, No. 4, pp.373-388.

Biographical notes: Carlos Martin-Rios is an Assistant Professor of Management at the Ecole Hôtelière de Lausanne, Switzerland. His current research interests are concerned with organisational innovation and renewal with an emphasis on services and knowledge-intensive work settings. In addition, he is also working on organisational control systems evolution, competitiveness, and innovation. Specifically, the organisational and behavioural aspects of work design and control solutions with an emphasis on people management in knowledge-intensive work settings. His recent work has been published in Journal of Management Inquiry, Journal of Business Research, Human Resource Management, or Research in Personnel and Human Resource Management.

\section{Introduction}

Organisational control systems are a central phenomenon that has been viewed through multiple theoretical lenses (Barley and Kunda, 1992; Ouchi, 1979; Tannenbaum, 1968). Control systems are made up of a number of norms, uses, and practices that convey the way individuals at multiple levels within an organisation must behave to achieve the organisation's objectives and give a satisfactory performance. A control system is a 
complex construct that may include a range of bureaucratic mechanisms including managerial and other human resource practices (Snell, 1992); formal regulating technology and information (Luhmann, 1995); and social, cultural and other informal means of control (Kunda, 1992; Ouchi, 1980). Underpinning the concept of an organisational control system are various perspectives about control norms and practices in the workplace. Frequently, the central focus in management and human resources theories is on individual performance and on the mechanisms available to management such that they can frame individual work objectives and align them with the expectations of the organisation (Bourne et al., 2003; Scott, 1995).

Questions remain about the manner in which individual task performance responds to organisational needs (Lilley et al., 2009). Some authors argue the need for more inclusive control systems that overcome the limits on individual task performance in the pursuit of higher-end, strategic goals and encourage individual participation in the business (Heckscher, 2007; Sabel, 2006). This seems more plausible in the context of knowledge work where individual goal attainment is less pervasive (Cardinal et al., 2004). In knowledge firms work occurs within the sphere of teamwork, where short-term, pragmatic collaborations with peers are necessary to cope with complexity, variability, and ambiguity in work output (Martin-Rios, 2014; Martin-Rios and Heckscher, 2014). These novel aspects of work need to be acknowledged in control systems, which poses challenges for the traditional notion of task performance dominant in more hierarchical, bureaucratic firms (Erhardt et al., 2009; Josserand et al., 2006).

However, despite the significance and theoretical richness of organisational control systems, the research agenda is limited, particularly in management and human resources literature (Sitkin et al., 2010). It has been shaped significantly by a top-down, command-and-control approach and by contingent models of goal-directed behaviour (Ouchi, 1977; Turner and Makhija, 2006) that view control systems as unilaterally directive configurations based on alternative paradigms, namely either that of rational control, which looks at the measurement of work outcomes (outcome control) and direct personal surveillance (behaviour control) or that of normative control, which emphasises power and moral authority (control of thoughts and emotions) by means of the organisational culture. This, in turn, has led to research dominated by a focus on management responsibility and hierarchical decision-making as the primary or even the only theoretical explanation for organisational control (Fisher, 1995; Holloway, 2001). Although this approach has yielded powerful insights, it has also constrained discourse. In contrast, consideration of alternative theoretical views will likely draw attention to different conceptions of control, and to organisations and environments where the logic of managerial control is less pervasive.

The purpose of this paper is to provide a deeper understanding of control systems in knowledge-intensive settings. The paper aims to offer theoretical insight into the individual level of analysis (Flamholtz et al., 1985). Although significant research has already been conducted within this framework, the present study seeks to expand this developing perspective by building additional conceptual bridges between human resource management research and the large, existing literature on organisation theory. In this essay, we suggest that knowledge-intensive firms place strong emphasis on aligning the traditional interests of individual performance with the need to build collaborative work relationships and shared decision-making as they seek to thrive. Organisational control stemming from the notion of individual contribution to the attainment of collective goals is proposed to better cope with increasing complexity in 
knowledge-intensive firms. We address these issues by introducing the notion of accountability. Accountability deals with the production of norms for self-regulation and the controls required to assess fulfilment of organisational requirements. Accountability makes self-regulation and social control possible. Self-regulation, in turn, helps individuals monitor and control their own behaviour, whereas social control forces individuals to be answerable in the fulfilment of their duties and obligations. In this way, we suggest that accountability is a multi-level construct that considers answerability to patterns of work group interaction as one of the components through which individual contribution is achieved. In this regard, it involves a sense of responsibility in several directions, namely towards superiors, peers, tasks, outcomes, and oneself. Here, the emphasis on accountability allows us to introduce a new, alternative perspective on organisational control systems. We propose that organisational control systems in knowledge-intensive firms rest primarily on the recognition of accountability by embracing the view that such accountability better addresses employee contribution.

This essay contributes to opening a discussion about various aspects of control in organisations by suggesting how accountability can promote a multi-level view of organisational control. By challenging the view that organisational control is either rational or normative, and always management-driven, we expand the theoretical debate on control systems in organisations. The article is structured as follows: first, past organisational control research is reviewed briefly. This is followed by an analysis of the limits of control systems in knowledge work. Next, we examine the notion of accountability in the context of organisational control systems, which is followed by a discussion of the implications. Our suggestions for future research conclude the paper.

\section{The antecedents of organisational control}

There are several theoretical approaches to control in organisations. Frequently, research on control proposes two alternative views of the modes of control: the bureaucratic or legal-rational mode and the normative or social mode of control (Barker, 1993; Barley and Kunda, 1992; Ouchi, 1979). From the rational-bureaucratic perspective, control systems are configurations of social and administrative mechanisms (both processes and techniques) associated to performance control. These mechanisms or modes of control are available to management so that they can frame individuals' work expectations and align them with the objectives of the organisation (Hellqvist, 2011; Martin-Rios and Erhardt, 2008). This perspective often views control systems as unidirectional directive configurations based either on measurement of outcomes (outcome control), direct personal surveillance (behaviour control), or on cultural and informal channels (clan control) (Ouchi, 1977).

A second approach views control systems as reflecting the symbolic basis of the organisational control discourse. It therefore discusses the uses of control systems by management rather than the actual practices. Effective control is attempted by several alternative forces - cognitive, normative and regulatory - and levels - corporate, management and operational - that help to delineate the range of individual or group responsibilities (Scott, 1995). Studies of normative control (Etzioni, 1964), coercive control (Sewell, 1998), or concertive control (Barker, 1993) try to account for the effect that the various forms of control can exert on the work process and on work relations 
(Ukko et al., 2008). Elements conducive to effective work management such as agency, culture, power, and ideology are relevant to this research. Specifically, recent developments in the literature on team dynamics, communities of practice, and professionals have advanced our knowledge regarding the normative and coercive aspects of organisational control in knowledge environments (Alvesson and Willmott, 2002; Ezzamel and Willmott, 1998; Kärreman and Alvesson, 2004; Styhre, 2008). Most of these studies focus on the informal, social side of control, leaving aside the formal aspect, which is often regarded as an essentially hierarchical form of control.

\subsection{Management of control systems}

Research on formal control tends to rely on cybernetic control (Aldrich, 1999; Turner and Makhija, 2006), defined as a model of behaviour production. Cybernetic control relies on three assumptions: first, there is a standard that corresponds to effective and efficient accomplishment of the organisation's objectives; second, actual accomplishment can be measured; and, finally, the standard can be compared against the measurement and variance information fed back to eliminate unwanted differences between measurement and standard in the future (Hofstede, 1978). The traditional cybernetic control cycle does not explicitly define the mechanisms of a control system, but rather defines the formal control process, such as performance measures and incentive compensation systems. A great deal of work on formal control in organisations reflects such a perspective from the cybernetic tradition. Specifically, one of its main uses is management by objectives (MBO) (Bradach and Eccles, 1989). This prospective control system is forward-looking in that it offers incentives for organisational actors to meet predetermined goals. Basically, the idea is to set measurable work objectives for individuals (the key unit of performance) based on the principles of predictability, homogeneity, and compliance with the rule (Locke and Latham, 1990). This form of control assumes that work processes and outputs are readily visible to those in authority.

When processes are unknown and outputs indeterminate, some note that management utilises informal, ritualised or social control (Eisenhardt, 1985). It is represented in a set of unwritten norms and values and exercised by management without explicitly stating these norms. Importantly, studies in management control find it difficult to reconcile the hierarchical system with the informal or social system, so the latter is often detached and dropped from formal control systems. Instead, the accepted focus is on a hierarchical system where the objective of efficient goal attainment (Blau and Scott, 1963) seems more plausible. In that regard, MBO-infused control systems exemplify the manner in which price and authority are efficient means of assessing and rewarding work outcomes and behaviour modifications in organisations (Drucker, 1954). To date, much research on management control systems is by and large committed to the study of control under rational logic control associated at hierarchical, bureaucratic firms.

\section{The limits of control system theory}

Knowledge plays an increasingly central role in organisations. There is a broad consensus that modern firms are becoming increasingly knowledge-intensive (Bell, 1973; Castells, 1996; Heckscher and Adler, 2006). There is also a growing view that knowledge work requires an alternative organisational form to traditional hierarchy (Heckscher, 2007). In 
general, these studies present a picture of knowledge-intensive organisations as horizontally designed work arrangements operating in uncertain and competitive contexts in pursuit of innovation and coordination of complex products or services (Blackler 1995; Erhardt et al., 2009; Parga et al., 2013). These organisations require knowledge work, defined as the "creation, coordination, integration and management of knowledge and information within a firm and its extended value network" (Conner and Prahalad, 1996). In this section, we highlight three main limitations to the above arguments on control theory concerning the organisational attributes of knowledge work: the question of contribution, the social elements of control, and the notion of collaboration.

\subsection{Individual contribution}

In the literature of organisations, individual performance frequently means results in the form of achievement of some predetermined goals or objectives. Because results can take several forms (e.g., output, quality or customer satisfaction), individual performance becomes a buzzword enclosing a variety of meanings around the notion of accomplishment. The definition of performance or accomplishment is the centrepiece of any organisational control system. For a system to succeed, it is essential that the definition of accomplishment be in consonance with control norms and practices. Task performance, the classic definition of accomplishment in bureaucracy, is often seen as a limited and inadequate measure of individual achievement in certain knowledge-intensive firms (Alvesson, 1995; Styhre, 2008). Authors such as Heckscher and Adler (2006, p.40) claim that in the knowledge firm organisational control must direct individuals toward the higher goal of contribution that "legitimizes attention to factors other than the immediate goal or task".

Contribution represents an alternative paradigm to task performance and constitutes an essential norm of accountability in knowledge settings (Heckscher, 2007). Individuals are accountable not only for accomplishing particular tasks and fulfilling performance requirements - the traditional outcome of employees in organisations - but also for contributing to strategic goals beyond their particular job. This requirement comes in the form of long-term and dynamic mission-driven objectives that are shared with peers and are attainable only through value-generating activities in some form of collaboration (Heckscher and Martin-Rios, 2013). Individual contribution emerges as the key coordinating value, as a consequence of the shift in focus from employee compliance to responsiveness and innovation (Heckscher and Adler, 2006), which calls for a redefinition of the traditional roles, tasks and obligations of individuals in the workplace. From this perspective, organisational control in knowledge work could then connect individual contribution to the broader success of the organisation.

\subsection{The social side of control}

The second limitation to hierarchical control is its inadequate attention to the social side of control systems. The relationship between formal and informal control mechanisms has not been explored thoroughly (Fisher, 1995). We have seen that informal relations between employees rooted in informal friendship or acquaintance are crucial to the stability of traditional hierarchical systems, where formal systems are just "the tip of the iceberg" (Heckscher and Donellon, 1994). However, management scholars have 
frequently been reluctant to include social or informal relations in their research on control. For example, Eisenhardt (1985) suggested differences between organisational and economic theory in recognising the 'people' or social strategy for control, but she intentionally excluded social control from her agency theory-based system of control. Snell (1992), when testing the control systems from a human resource perspective, used 'informal' or 'social control' to refer to direct supervision and feedback. He found that social control, even in this limited sense, was ambiguous from the human resource point of view because it was rooted in culture and informal exchanges rather than objective behaviours and outputs.

The conditions for knowledge work raise issues regarding the emphasis on formal control systems (Cardinal et al., 2004). We underline several theoretical issues with respect to social control dimensions. First, in traditional control theory 'social' is equated with 'informal' and thus seen as inherently unmanageable. It suggests that social control works only when interpersonal relations among employees are rooted in informal ties of friendship or acquaintance; but this logic prevents people from formalising collaborative relationships with peers. In contrast, in knowledge settings, dynamic social processes and relations are central to the success of these firms (Erhardt et al., 2014; Gardner et al., 2011). It is through collaboration and promotion of social relations that knowledge creation and sharing flourish (Erhardt, 2011). Thus, the trend is toward the acknowledgement and increasing formalisation of previously informal work relations and practices (Heckscher, 2007). In these settings, the boundaries between formal and informal spheres of work are, in a way, disappearing and greater recognition of this pattern will facilitate the fuller development and use of organisational control systems. These fundamental alterations of social relations in the workplace bring new practices and symbols of control into everyday use.

\subsection{Collaboration}

In knowledge-intensive firms, work occurs within the sphere of teamwork, where short-term, pragmatic collaborations with peers are necessary to cope with complexity, variability, and ambiguity in work output. Collaboration emerges as a way of attaining ill-defined, complex goals while stressing the need for working together across formal boundaries (Heckscher, 1994; Mohrman et al., 1995). Collaboration means that individuals do not work in isolation and are not motivated to do so: it promotes interdependence over independence. To effectively contribute to the organisation's strategy, multiple commitments rather than an ordered hierarchy of commitments are needed. These novel aspects of work need to be acknowledged in the control system. If their perceptions of the control system are positive, individuals will be more predisposed to collaborate and share their knowledge with others, whereas if their perceptions of the system are negative, they will tend to avoid collaborating with others.

Collaboration implies bringing together a diverse pool of skills and working toward one common mission by means of pragmatic reciprocity. Heterogeneous teams are commonplace as they incorporate membership diversity (in terms of skills, interests and backgrounds) which is conducive to innovation and problem solving (Erhardt, 2011; Erhardt et al., 2009). The principle of diversity overcomes that of homogeneity in bureaucracy. The creation of a group identity over longstanding, informal bonds of loyalty and shared norms and objectives that are common in bureaucratic organisations is 
defied in knowledge work by more short-term project-driven relationships. However, such diversity challenges not only autonomy and consensus-seeking relationships among equals but also forms of authority based on hierarchical relationships, all of which constitute a challenge to hierarchical control systems because they make it harder to conform and to defer to hierarchy. To be effective, control systems require reciprocity the willingness to give and take. Otherwise membership diversity, a key ingredient in achieving learning and collaboration, constitutes an element of tension in the control system ('how does somebody from outside my group come and challenge what I am doing and tell me what to do?')

Contributing to higher-order strategic objectives seems difficult to reconcile with the requirements of hierarchical, objective based control systems. In knowledge work, organisational control stemming from the notion of individual contribution to the attainment of collective goals is proposed to better cope with increasing complexity in an organisational setting. This implies that decentralised decision-making, collaborative mechanisms, and formal control principles should be built through shared consensus. As Adler and Heckscher (2006, p.43) point out, "there is not one boss to please, but an entire network of collaborating partners". In the absence of concrete measures to limit disputes, the organisation's strategic goals and operational targets become increasingly challenging. Therefore, the more knowledge-driven the organisation, the more challenging we would expect the usefulness of the hierarchical system to be.

\section{The nature of accountability in knowledge work}

The argument we advance here extends existing perspectives on the study of control systems in organisations by examining the significance of new forms of governance associated with the notion of accountability. Since organisations are changing, we assume that some concepts that were useful in the past now need to be generalised and abstracted. Two distinct yet interrelated conceptualisations of organisational control phenomena are central to the discussion. The broadest of these constructs is contribution, which, as explained in the previous section, we define as the notion that indicates to individuals the expectations surrounding their participation in the work process. The other construct is accountability, which, is both an integral component of the organisational control system and one of its key representations in organisations. Hierarchical systems are one form of organisational control system, the latter concept being more general. Hierarchical control is increasingly at odds with the needs of knowledge work. Yet no uniform conceptualisation of an alternative system to hierarchical control has been offered to date. We will argue that, based on the logic of contribution, organisational control in knowledge settings requires accountability to be emphasised.

\subsection{Conceptualising accountability}

Accountability can be defined on two dimensions. One relates to the individual nature of answerability. Individuals respond to demands to effectively engage in constructive 
outcomes (Tetlock, 1998). In everyday life they are held accountable for a myriad of duties and responsibilities, including family, friends, and community. The workplace is no exception (for a survey of general issues in the analysis of individual accountability in organisations, see Frink and Klimoski, 2004). Here, accountability is parallel to the concept of answerability (Frink and Klimoski, 1998). The other aspect refers to the organisational level at which individual accountabilities are to be found. Such a system provides a sense of direction and makes individuals conform to the requirements of execution and accomplishment (Roberts, 1991).

Although the notion of accountability has been used in management and sociological literature (Heckscher, 2007; Simons, 2005), it still lacks a formal, commonly accepted definition. We propose that in organisations, accountability function as an 'operating system' that coordinates the needs and requirements of multiple constituencies (supervisors, peers, subordinates, and oneself) to trigger the desired behaviour and work achievement. In the accountability system, significant emphasis is placed on meeting the following three demands for improving organisational performance (for what to be held to account?) by connecting human behaviour (whom to hold to account?) with the norms, mechanisms, and practices (how and when to be held to account?) underpinning strategic success.

To effectively manage accountability, control systems in knowledge organisations should encompass both instrumental and ethical dimensions. Whereas the first deals with the controls required to assess whether organisational requirements have been fulfilled, the ethical dimension focuses on the production of norms for self-regulation. In this regard, as Giddens (1984, p.30) points out, "to be accountable for one's activities is both to explicate the reasons for them and to supply normative grounds whereby they may be justified". In this way, we argue that control systems that promote accountability become more ambitious and comprehensive in their scope and are framed so as to involve a sense of responsibility in several directions: toward superiors, the task, the outcome, and oneself (Munro and Mouritsen, 1996).

Accountability makes self-regulation and social control possible (Schlenker and Weigold, 1989). Self-regulation helps individuals monitor and control their own behaviour, whereas social control forces individuals to be answerable in fulfilling duties and obligations (Frink and Klimoski, 2004). Answerability varies according to the degree of individual involvement in the fulfilment of duties and obligations. Thus, we suggest that accountability can represent an organisational response to the need to provide individuals with a set of norms and mechanisms that assess, reward, punish, and recognise the accomplishment of duties and responsibilities as well as their participation in work processes and work outcomes. The distinction between organisational control systems that take accountability into consideration is important. Sabel (2006, p.123) suggests that accountability involves a subjective form of control, especially in knowledge work; he defines the social rules operating there as "systems where the external and internal web of accountabilities live together". In contrast, traditional organisational control systems rest primarily on management responsibility and hierarchical decision-making as a primary source of organisational control. Table 1 below illustrates these elements. The use of this typology helps to frame the discussion of accountability and place boundaries on the dimensions (why, who, how) within which the control system is operating. The following sections elucidate the core elements of each of these dimensions. 
Table 1 Two logics of control

\begin{tabular}{|c|c|c|c|}
\hline & For what & Who & How and when \\
\hline & \multicolumn{3}{|c|}{ Be held to account } \\
\hline Bureaucracy & $\begin{array}{l}\text { Performance: } \\
\text { (efficient goal } \\
\text { attainment) }\end{array}$ & $\begin{array}{l}\text { - Individual (attribution } \\
\text { and compliance) } \\
\text { - } \quad \text { Self and superior }\end{array}$ & $\begin{array}{ll}\text { - } & \text { MBO: top-down } \\
\text { - } & \text { Tied to task } \\
\text { performance } \\
\text { - } & \text { Prospective } \\
\end{array}$ \\
\hline $\begin{array}{l}\text { Knowledge } \\
\text { work }\end{array}$ & Contribution & $\begin{array}{l}\text { - Individual (reflexivity } \\
\text { and interdependence) } \\
\text { - Shared (multiple } \\
\text { views) }\end{array}$ & $\begin{array}{ll}\text { - } & \text { Multisource } \\
\text { - } & \text { Tied to strategy } \\
\text { - } & \text { Retrospective }\end{array}$ \\
\hline
\end{tabular}

\subsection{Multiple views at different levels}

In knowledge work, accountability occurs at all levels of the organisation. Individuals are usually accountable to all those with whom they interact (interdependence) rather than to a single hierarchical superior (dependence), which implies the formalisation of shared accountability - active participation of all incumbents in the work process (supervisors, peers, subordinates, and customers). A control system based on accountability is dynamic rather than static, requiring individual responsiveness to the process rather than compliance with a unilaterally imposed set of regulatory practices. Indeed, this view adds new elements of reflexivity to accountability norms. This includes self-control or retrospective accountability (Bandura, 1997). Self-regulation forces accountable individuals to monitor and control their own behaviour and accomplishments in order to understand how their contribution is achieved and to develop strategies for collaborating based on individual capabilities and limitations.

Together with self- and top-down supervision, it is essential to focus on the group elements of accountability (Simons, 1995). In knowledge work, individuals need each other's knowledge and capabilities to succeed in their work. At the group level, accountability can be ensured through interaction or peer pressure (Antonioni, 1994). Frequently through membership allegiance, individuals in the same group sanction each others' conduct (Lazega, 2000). The sanctioning process may use accountability as a medium or an outcome resulting in either inclusion or exclusion (Barker, 1993; Sewell, 1998). Individuals have to determine whether their decisions are actually contributing positively not just to their own success but also to that of their peers and to the broader organisational performance. For instance, Sabel (2006) summarises the social component of accountability:

"Accountable behaviour in this setting no longer entails compliance in the sense of rule following, but rather provision of a compelling explanation for choosing, in the light of fresh knowledge, one way of achieving the common (sub) goal over others. At the limit, principal-agent accountability gives way to peer review, in which decision makers learn from and correct each other even as they set goals and performance standards for the organization." (p.144) 


\subsection{Foundations of accountability mechanisms}

The accountability problem emphasises disconnection between organisational requirements and existing formal mechanisms of control. In most of the extant literature on human resources, control practices are analysed in isolation, without taking into account their connection with the larger organisation control system, its norms and values. A common consequence is excessive attention to individual performance isolated from the long-term, organisational objectives. This drives organisations to leave aside aspects of contribution and to focus instead on a set of narrow practices for framing and rewarding task objectives (Duckett and Langford, 2013). Addressing the quest for contribution requires a broad revision of the role of individuals in organisational success and the way it is incorporated into the control mechanisms. To help illustrate this point, we consider the two sets of control mechanisms, i.e., assessment and sanction.

Assessment practices are critical elements of control systems because they convey the message about actual work expectations, set the technical procedure to appraise accomplishment, and provide arguments for sanctioning (reward or punishment). They must be selected in accordance with the actual control norms. Control systems centred on the notion of accountability necessitate tools that judge whether individuals have made a contribution to the larger organisation. Assessment mechanisms proposed in this work must address both aspects of contribution:

1 the associative, multi-source foundation of employee work outcomes

2 the level of contribution to the organisation's mission and strategy.

Determining the drivers of individual work outcomes turns into a multi-faceted exercise when the notion of contribution is considered. Multi-source, 360 degree, or multi-rater appraisal tools embody a departure from the more restricted supervisor-subordinate interaction and engage multiple constituencies in the review process. Not only is the stress of these tools shifting from observable measures of performance to more developmental concerns, but they also make explicit the role that peers have on individual work roles and outcomes (Peiperl, 2001). A key assumption underlying multisource appraisal is that individuals benefit from knowing how others evaluate their performance (London et al., 1997). This is especially relevant in knowledge settings where tools that reflect the ways in which employee contribution, responsibilities, and work outcomes are exposed to multiple constituencies (Testa, 2002), not just superiors, peers, and subordinates within the organisation, are an essential element of the organisational control system.

The second requirement may be achieved through tools that focus on strategy, such as 'strategic scorecards'. Strategic scorecards provide a framework for translating the mission and strategy into a set of objectives and quantifiable measures that collectively capture the requirements most critical to the continued success of the organisation (Kaplan and Norton, 1996). Although there has been extensive research on the uses of strategic scorecards, much of this research has focused on organisational performance measurement as the main purpose of the tool (Kaplan and Norton, 2001). When indicators are designed to help monitor individual progress towards achieving business objectives, the instrument may be suitable to accountability. In this way, strategic scorecards make it possible to drive strategic awareness throughout the system, connecting assessments, rewards and sanctions to these requirements. 
In addition to assessment, accountability requires a system of sanctions (Covaleski et al., 1998). These can be both positive sanctions (including incentives, praise, and promotion) and negative sanctions (i.e., criticism, shame, demotion, and firing) (Tenbrunsel and Messick, 1999). Sanctioning mechanisms contain all of these practices and give them direction and a sense of unity. Overall, sanctioning mechanisms are a powerful motivational tool driving decisions and actions that are consistent with the espoused strategy. Control theory examines a few key sanctioning practices, particularly compensation, benefits, and career advancement. An accountability perspective includes these practices, but also adds awareness of informal sanctions arising from peer approval and other group dynamics, and tries to align these informal sanctions more deliberately with the goals of the organisation. In this sense, reputation emerges as a powerful instrument to reward contribution (Kilduff and Krackhardt, 1994). In hierarchical control systems, reputation usually operates informally through word-of-mouth and is disconnected from the formal process; its connection to organisation goals is uncertain. In knowledge settings, reputation is increasingly determined by the degree to which individuals are effective at meeting the expectations of each of their peers, subordinates and superiors. In this sense, the inclusion of reputation in the control system represents a form of formal social recognition of employee contribution. In turn, it becomes a critical sanction; people shape their behaviour to enhance their reputation (Jones et al., 1997). An initial proposition connecting individual and performance reputation is presented by Kilduff and Krackhardt (1994, p.88), when they assert: "The higher an individual's reputation, the more valuable he or she becomes in the internal labour market".

In essence, given the reliance on collaborative arrangements that exists in knowledge work, assessing and sanctioning an individual's contribution to higher-order outcomes entails active involvement of all participants in the work process (supervisors, peers, subordinates, and customers). Supervisors alone might not hold all the necessary information to assess and sanction individual contribution. Hence, knowledge environments provided conditions amenable to shared (collaborative) accountability approaches but detrimental to hierarchical forms.

\section{Conclusions}

The purpose of this article has been to contribute to research on organisational control. We have proposed that by viewing organisational control through the lens of accountability, we can better understand how and why governance works in knowledge-intensive settings. Research suggests that control systems include bureaucratic, normative, and a combination of formal and informal components developed to measure and secure compliance with control norms, to reward and reinforce desired behaviours and outputs and to punish and discourage undesired behaviours (Turner and Makhija, 2006). The thesis of this article is that organisations in complex, knowledge-intensive environments are required to implement control systems that replace directive, hierarchy-driven control systems. It argues that although such systems are beneficial for organisations in stable contexts, they are fundamentally inconsistent with all but incremental demand for contribution as required in the new organisational paradigm. A hierarchical system often means centralised decision-making (Drucker, 1954), a standard practice likely to collide in knowledge work where so many 
organisational requirements concur at any given time (Martin-Rios et al., 2014). Centralised decision-making concentrates knowledge about the control model, its norms and mechanisms, and its implementation and outcomes outside non-managerial organisational members. However, in knowledge work, firm success rests on the ability of these groups to engage in collaborative decision-making (Heckscher and Adler, 2006). The exclusion of employees from decision-making regarding accountability issues has negative consequences for the legitimacy of the entire control system. Furthermore, an excessive focus on individual performance leads to difficulties in collaborative environments, and is even more problematic when managed by the logic of control by objectives. In knowledge settings, organisational control needs to connect individual contribution with the broader success of the organisation. Objective based systems and clear operating rules may restrain the individual's ability to act in a collaborative and contribution-driven manner, which results in overemphasis on quantitative individual objectives at the expense of contribution to the team and to the organisation at large.

Whereas the other theories view control merely from the management point of view, none of them consider patterns of work group interaction as one of the components leading to contribution. We propose that individual and group elements of shared accountability become essential elements of control systems in complex, knowledge work. In this way, we suggest that a greater focus on individual (self) and group elements of accountability may help ensure the success of organisational control systems. Accountability sets transparency, which is the first step in enabling everyone - at every level of the organisation - to explore their own contribution in search of actionable insights. Similarly, we argue that knowledge firms hesitant to introduce mechanisms that specifically address accountability in their control systems may provoke tension among individuals as a result of the discrepancy between organisational needs and the control system in place, thereby diminishing the attainment of organisational objectives and, ultimately, the effectiveness of the organisation.

Further research on accountability in knowledge work could focus on current governance and control mechanisms put in place by firms to determine the issues for which people are held accountable. More work is needed to uncover the way in which these firms establish formal practices and mechanisms of accountability built around the notion of contribution. The examination of alternative theoretical views of organisational control will likely draw attention to different conceptions of social control. Also, such approaches may lead to novel understandings of organisation-individual relations in knowledge environments and new theories of organisational behaviour.

The proposed approach to organisational control has a number of implications for practitioners. First, it highlights the importance of broadening the scope of responsibility. Prior research has found that a multi-level perspective on governance is crucial for organisational control in complex knowledge work. However, organisational control focused on accountability is a concept that organisations are only just beginning to come to grips with. Frequently, the difficulty in establishing new systems and the absence of immediate and pervasive outcomes may persuade firms to retain practices designed to obtain outcomes other than contribution and to adjust their systems by making only minor modifications to existing practices. We suggest that organisational control rooted in the notion of accountability increases the perceived overall effectiveness of the system. 


\section{References}

Aldrich, H. (1999) Organizations Evolving, Sage Publication, Thousand Oaks, CA.

Alvesson, M. (1995) Management of Knowledge-Intensive Companies, Walter de Gruyter, Berlin.

Alvesson, M. and Willmott, H. (2002) 'Producing the appropriate individual: identity regulation as organizational control', Journal of Management Studies, Vol. 39, No. 5, pp.619-644.

Antonioni, D. (1994) 'The effects of feedback accountability on upward appraisal ratings', Personnel Psychology, Vol. 47, No. 2, pp.349-356.

Bandura, A. (1997) Self-Efficacy: The Exercise of Control, Freeman, New York.

Barker, J.R. (1993) 'Tightening the iron cage: concertive control in self-managing teams', Administrative Science Quarterly, Vol. 38, No. 3, pp.408-437.

Barley, S.R. and Kunda, G. (1992) 'Design and devotion: surges of rational and normative ideologies of control in managerial discourse', Administrative Science Quarterly, Vol. 37, No. 3, pp.363-399.

Bell, D. (1973) The Coming of Post-Industrial Society, Basic Books, New York.

Blackler, F. (1995) 'Knowledge, knowledge work and organizations: an overview and interpretation', Organization Studies, Vol. 16, No. 6, pp.1021-1046.

Blau, P.M. and Scott, W.R. (1963) Formal Organizations, Routledge and Kegan Paul, London.

Bourne, M., Neely, A., Mills, J. and Platts, K. (2003) 'Implementing performance measurement systems: a literature review', International Journal of Business Performance Management, Vol. 5, No. 1, pp.1-24.

Bradach, J. and Eccles, R. (1989) 'Price, authority, and trust', Annual Review of Sociology, Vol. 15, pp.97-118.

Cardinal, L.B., Sitkin, S.B. and Long, C.P. (2004) 'Balancing and rebalancing in the creation and evolution of organizational control', Organization Science, Vol. 15, No. 4, pp.411-431.

Castells, M. (1996) The Information Age: Economy, Society and Culture, Volume I: The Rise of the Network Society, Blackwell Publishers, Malden, MA.

Conner, K.R. and Prahalad, C.K. (1996) 'A resource-based theory of the firm: knowledge versus opportunism', Organization Science, Vol. 7, No. 5, pp.477-501.

Covaleski, M.A., Dirsmith, M.W., Heian, J.B. and Samuel, S. (1998) 'The calculated and the avowed: techniques of discipline and struggles over identity in Big Six public accounting firms', Administrative Science Quarterly, Vol. 43, No. 2, pp.293-327.

Drucker, P. (1954) The Practice of Management, Harper \& Row, New York.

Duckett, H. and Langford, N. (2013) 'Delivering modernisation through a total reward framework? A UK Government agency case study', International Journal of Business Performance Management, Vol. 14, No. 1, pp.52-66.

Eisenhardt, K. (1985) 'Control: organizational and economic approaches', Management Science, Vol. 31, No. 2, pp.134-149.

Erhardt, N. (2011) 'Is it all about teamwork? Understanding processes in team-based knowledge work', Management Learning, Vol. 42, No. 1, pp.87-112.

Erhardt, N., Martin-Rios, C. and Harkins, J. (2014) 'Knowledge flow from the top: the importance of teamwork structure in team sports', European Sport Management Quarterly, Vol. 14, No. 4, pp.375-396.

Erhardt, N., Martin-Rios, C. and Way, S. (2009) 'From bureaucratic forms towards team-based knowledge work systems: implications for human resource management', International Journal of Collaborative Enterprise, Vol. 1, No. 2, pp.160-179.

Etzioni, A. (1964) Modern Organizations, Prentice-Hall, Englewood Cliffs.

Ezzamel, M. and Willmott, H. (1998) 'Accounting for teamwork: a critical study of group-based systems of organizational control', Administrative Science Quarterly, Vol. 43, No. 2, pp.358-396. 
Fisher, J. (1995) 'Contingency-based research on management control systems', Journal of Accounting Literature, Vol. 14, No. 1, pp.24-53.

Flamholtz, E., Das, T. and Tsui, A. (1985) 'Toward an integrative framework of organizational control', Accounting, Organizations and Society, Vol. 10, No. 1, pp.35-50.

Frink, D.D. and Klimoski, R.J. (1998) 'Toward a theory of accountability in organizations and human resource management', in Ferris, G.R. (Ed.): Research in Personnel and Human Resources Management, Vol. 16, pp.1-51, Jai Press, CT.

Frink, D.D. and Klimoski, R.J. (2004) 'Advancing accountability theory and practice: introduction to the human resource management review special edition', Human Resource Management Review, Vol. 14, No. 1, pp.1-17.

Gardner, T.M., Erhardt, N.L. and Martin-Rios, C. (2011) 'Rebranding employment branding: establishing a new research agenda to explore the attributes, antecedents, and consequences of workers' employment brand knowledge', Research in Personnel and Human Resources Management, Vol. 30, pp.253-304.

Giddens, A. (1984) The Constitution of Society: Outline of the Theory of Structuration, Polity Press, Cambridge.

Heckscher, C. (1994) 'Defining the post-bureaucratic type', in Heckscher, C. and Donellon, A. (Eds.): The Post-Bureaucratic Organization, pp.14-62, Oxford University Press, New York.

Heckscher, C. (2007) The Collaborative Enterprise, Yale University Press, New Haven, CT.

Heckscher, C. and Adler, P. (2006) Collaborative Community, Oxford University Press, New York.

Heckscher, C. and Donellon, A. (1994) The Post-Bureaucratic Organization, Oxford University Press, New York.

Heckscher, C. and Martin-Rios, C. (2013) 'Looking back, moving forward: toward collaborative universities', Journal of Management Inquiry, Vol. 22, No. 1, pp.136-139.

Hellqvist, N. (2011) 'Global performance management: a research agenda', Management Research Review, Vol. 34, No. 8, pp.927-946.

Hofstede, G. (1978) 'Poverty of management control philosophy', Academy of Management Review, Vol. 3, No. 3, pp.450-461.

Holloway, J. (2001) 'Investigating the impact of performance measurement', International Journal of Business Performance Management, Vol. 3, No. 2, pp.167-180.

Jones, C., Hesterly, W.S. and Borgatti, S. (1997) 'A general theory of network governance: exchange conditions and social mechanisms', Academy of Management Review, Vol. 22, No. 4, pp.911-945.

Josserand, E., Teo, S. and Clegg, S. (2006) 'From bureaucratic to post-bureaucratic: the difficulties of transition', Journal of Organizational Change Management, Vol. 19, No. 1, pp.54-64.

Kaplan, R.S. and Norton, D.P. (1996) 'Using the balanced scorecard as a strategic management system', Harvard Business Review, January-February, Vol. 74, No. 1, pp.75-85.

Kaplan, R.S. and Norton, D.P. (2001) 'Transforming the balanced scorecard from performance measurement to strategic management', Accounting Horizons, Vol. 15, No. 1, pp.87-104.

Kärreman, D. and Alvesson, M. (2004) 'Cages in tandem: Management control, social identity, and identification in a knowledge-intensive firm', Organization, Vol. 11, No. 1, pp.149-175.

Kilduff, M. and Krackhardt, D. (1994) 'Bringing the individual back in: a structural analysis of the internal market for reputation in organizations', Academy of Management Journal, Vol. 37, No. 1, pp.87-108.

Kunda, G. (1992) Engineering Culture: Control and Commitment in a High-Tech Organization, Temple University Press, Philadelphia.

Lazega, E. (2000) 'Rule enforcement among peers: a lateral control regime', Organization Studies, Vol. 21, No. 1, pp.193-214.

Lilley, S., Wray-Bliss, E. and Linstead, S. (2009) 'Organisational control', in Linstead, S., Fulop, L. and Lilley, S. (Eds.): Management and Organization - A Critical Text, pp.319-356, Palgrave Macmillan, Basingstoke, UK. 
Locke, E.A. and Latham, G.P. (1990) A Theory of Goal Setting and Task Performance, Prentice Hall, Englewood Cliffs, NJ.

London, M., Smither, J.W. and Adsit, D.J. (1997) 'Accountability: the Achilles' heel of multisource feedback', Group \& Organization Management, Vol. 22, No. 2, pp.162-184.

Luhmann, N. (1995) Social Systems, Stanford University Press, Stanford, CT.

Martin-Rios, C. (2014) 'Why do firms seek to share human resource management knowledge? The importance of inter-firm networks', Journal of Business Research, Vol. 67, No. 2, pp.190-199.

Martin-Rios, C. and Erhardt, N. (2008) 'Organisational knowledge transfer through human resource management: international diffusion of managerial performance management', European Journal of International Management, Vol. 2, No. 2, pp.170-191.

Martin-Rios, C. and Heckscher, C. (2014) 'Rekindling university organizational model', Revista Internacional de Sociología, Vol. 72, No. 1, pp.247-248.

Martin-Rios, C., Heckscher, C. and Gonzalez, C. (2014) 'Unfurling organizational innovation in public services: the case of a public research organization', in Hervas J.L. and Peris, M. (Eds.): Management Innovation, pp.61-74, Springer International Publishing.

Mohrman, S., Cohen, S. and Mohrman, A. (1995) Designing Team-Based Organizations, Jossey-Bass, San Francisco, CA.

Munro, R. and Mouritsen, J. (1996) Accountability: Power, Ethos and the Technologies of Managing, International Thomson Business Press, London.

Ouchi, W. (1977) 'The relationship between organizational structure and organizational control', Administrative Science Quarterly, Vol. 22, No. 1, pp.95-113.

Ouchi, W. (1979) 'A conceptual framework for the design of organizational control mechanisms', Management Science, Vol. 25, No. 9, pp.833-848.

Ouchi, W. (1980) 'Markets, bureaucracies and clans', Administrative Science Quarterly, Vol. 25, No. 1, pp.129-141.

Parga, E., Martin-Rios, C. and Criado, F. (2013) 'Organizational and management innovation as a driving force of business renewal', Journal of Technology Management Innovation, Vol. 8, No. 2, pp.132-143.

Peiperl, M. (2001) 'Getting 360 degree feedback right', Harvard Business Review, January, Vol. 79, No. 1, pp.142-147.

Roberts, J. (2001) 'Trust and control in Anglo-American systems of corporate governance: the individualizing and socializing effects of processes of accountability', Human Relations, Vol. 54, No. 12, pp.1547-1572.

Sabel, C. (2006) 'Theory of a real-time revolution', in Heckscher, C. and Adler, P. (Eds.): Collaborative Community, pp.106-157, Oxford University Press, New York.

Schlenker, B.R. and Weigold, M.F. (1989) 'Self-identification and accountability', in Giacalone, R.A. and Rosenfeld, P. (Eds.): Impression Management in the Organization, pp.21-43, Lawrence Erlbaum, NJ.

Scott, A. (1995) Institutions and Organizations, Sage Publications, Thousand Oaks, CA.

Sewell, G. (1998) 'The discipline of teams: the control of team-based industrial work through electronic and peer surveillance', Administrative Science Quarterly, Vol. 43, No. 2, pp.397-428.

Simons, R. (1995) 'Control in an age of empowerment', Harvard Business Review, March-April, pp.80-88.

Simons, R. (2005) Levers of Organization Design, Harvard Business School Press, Boston, MA.

Sitkin, S.B., Cardinal, L.B. and Bijlsma-Frankema, K. (2010) Organizational Control, Cambridge University Press, Cambridge.

Snell, S. (1992) 'Control theory in strategic human resource management', Academy of Management Journal, Vol. 35, No. 2, pp.292-327. 
Styhre, A. (2008) 'Management control in bureaucratic and post-bureaucratic organizations', Group \& Organization Management, Vol. 33, pp.635-656.

Tannenbaum, A.S. (1968) Control in Organizations, McGraw-Hill, New York.

Tenbrunsel, A. and Messick, D. (1999) 'Sanctioning systems, decision frames, and cooperation', Administrative Science Quarterly, Vol. 44, pp.684-707.

Testa, M.R. (2002) 'A model for organization-based 360 degree leadership assessment', Leadership \& Organization Development Journal, Vol. 23, No. 5, pp.260-268.

Tetlock, P. (1998) 'Losing our religion', in Kramer, R. and Neale, M. (Eds.): Influence Processes in Organizations: Emerging Themes in Theory and Research, pp.121-144, Sage Publications, Thousand Oaks, CA.

Turner, K.L. and Makhija, M.V. (2006) 'The role of organizational controls in managing knowledge', Academy of Management Review, Vol. 31, pp.197-217.

Ukko, J., Tenhunen, J. and Rantanen, H. (2008) 'The impacts of performance measurement on the quality of working life', International Journal of Business Performance Management, Vol. 10, No. 1, pp.86-98. 